\title{
PRODUÇÃO DE FRUTOS DE LARANJ EIRA PÊRA E TEORES DE NUTRIENTES NAS FOLHAS E NO SOLO, EM LATOSSOLO VERMELHO-ESCURO DO NOROESTE DO PARANÁ(1)
}

\author{
J . FIDALSKI (2), M. A. PAVAN ${ }^{(3)}$,P.A.M.AULER ${ }^{(4)}$ \& A.P.J ACOMINO(5)
}

\begin{abstract}
RESUMO
A cobertura vegetal das entrelinhas dos pomares cítricos é uma prática necessária nos solos arenosos originári os da formação geológica do arenito Caiuá do Paraná. $O$ estudo foi realizado em um experimento de laranjeira pêra sobre o porta-enxerto limão-cravo instalado no campo em 1993, no município de Alto Paraná, em um Latossolo Vermelho-E scuro, onde estavam sendo avaliados seis diferentes sistemas de manejo do solo das entrelinhas do pomar. Na safra agrícola de 1995/96, foram coletadas amostras de folha e solo nas entrelinhas e faixas de adubação nas camadas de 0-20 e 20-40 cm e avaliados a produção e o número de frutos. A produção e o número de frutos correlacionaram-se, positivamente, com as características químicas do solo $\mathrm{Ca}, \mathrm{Mg}, \mathrm{pH}$ e $\mathrm{V}$ das entrelinhas do pomar e, negativamente, com Al e H + Al. Os teores foliares de Ca correlacionaram-se, positivamente, com a produção e o número de frutos. $\mathrm{O}$ nível crítico de $\mathrm{Ca}$ nas folhas foi de $29,72 \mathrm{~g} \mathrm{~kg}^{-1}$.
\end{abstract}

Termos de indexação: Citrus sinensis, diagnose foliar, acidez do solo, cálcio.
SUMMARY: PEAR ORANGE FRUIT YIELD AND NUTRIENT LEVELS OF LEAF AND SOIL IN A DARK-RED LATOSOL IN NORTHWEST PARANÁ, BRAZIL

Vegetative soil cover between citrus tree rows in sand soils originated from Caiuá sandstone geological formation in the northwest of the state of Parana, Brazil is a management practicerequired to protect soil from erosion. A field experiment was set up in 1993 in a citrus orchard with pear orangeon rangpur limerootstock located at Al to Paraná.

(1) Trabalho apresentado no XV Congresso Brasileiro de Fruticultura, Poços de Caldas, 18 a 23 de outubro de 1998. Recebido para publicação em março de 1997 e aprovado em dezembro de 1998.

(2) Pesquisador do Instituto Agronômico do Paraná (IAPAR). Caixa Postal 564, CEP 87701-970 Paranavaí (PR). E-mail: fidalski@or.gov.br.

(3) Pesquisador do IAPAR. Caixa Postal 481, CEP 86001-970 Londrina (PR).

(4) Pesquisador do IAPAR. Caixa Postal 564, CEP 87701-970 Paranavaí (PR). E-mail: aulerpe@pr.gov.br.

(5) Professor do Departamento de Horticultura, Escola Superior de Agricultura Luiz de Queiroz, ESALQ/USP. Caixa Postal 9, CEP 13418-900 Piracicaba (SP). E-mail: jacomino@carpa.ciagri.usp.br. 
Six types of soil management were evaluated in the 1995/ 1996 season and the following was determined: fruit yie ds (total weight and number), leaf samples, and soil samples were taken from 0-20 and 20-40 cm soil depth in the zone of fertilizer application and at the center between tree rows. The results showed that citrus yields were positively correlated with soil $\mathrm{Ca}, \mathrm{Mg}, \mathrm{pH}$, and base saturation, and negatively correlated with soil Al and total acidity $(\mathrm{H}+\mathrm{Al})$, in center between tree rows. Leaf $\mathrm{Ca}$ was positively related with citrus yiedds. The critical leaf Ca concentration was $29.72 \mathrm{~g} \mathrm{~kg}^{-1}$.

Index terms: Citrus sinensis, foliar diagnosis, soil acidity, calcium.

\section{NTRODUÇÃO}

A partir de 1988, pomares de Iaranja foram implantados em solos originários da formação geológica "Caiuá", arenito deocorrência predominante na região N oroeste do Paraná, caracterizado pela textura arenosa na camada arável (EMBRAPA, 1984) e baixa fertilidade. Apresenta em média $5,7 \mathrm{~g} \mathrm{dm}^{-3}$ de carbono, capaci dade detroca de cátions de 49,8 mmol dm$^{-3}$, saturação por bases de 42,8\% e baixa acidez com saturação por alumínio de 10,3\% (Fidalski, 1997a).

Nessas condições, a sustentabilidade da citricultura é dependente da manutenção da cobertura vegetal nas entrelinhas dos pomares, visando controlar a erosão hídrica do tipo laminar, comum nas lavouras permanentes de cafeeiros e amoreirais (Fidalski, 1997b). Chegou-se a cogitar a manutenção das gramíneas quando da implantação de pomares em áreas de pastagens (IAPAR, 1992), que ocupam aproximadamente $70 \%$ da área agrícola desta região.

O efeito do manejo do solo das entrelinhas na nutrição da Iaranjeira Hamlin enxertada em laranjeira caipi ra foi obtido com mulching decapimgordura e adubação verde com mucuna preta, que aumentaram os teores foliares de fósforo (Gallo \& Rodrigues, 1960). Na formação delaranja pêra sobre tangerina Cleópatra, o manejo de Crotalaria juncea, guandu e feijão-de-porco foram as espécies mais adequadas à pratica de adubação verde, contribuindo na redução da apli cação denitrogênio mineral (Silva, 1995).

A manutenção da cobertura vegetal nas entrel inhas dos pomares de citros é imprescindível em solos originários do arenito Caiuá no Noroeste do Paraná, dada a redução do teor de carbono observado com o preparo do solo convencional para a implantação da citricultura em áreas anteriormente ocupadas pelas pastagens, restabelecidos após a cobertura vegetal das entrelinhas (Fidalski \& Auler, 1997).

A inexistência de estudos de correlação entre os nutrientes desses sol os com os nutrientes foliares e a produção de citros mantém indefinido o efeito do manejo do solo das entrelinhas na nutrição e produção de frutos.

O objetivo destetrabalhofoi avaliar, em condições de campo, as relações entre a produção de frutos da laranjeira pêra e os nutrientes das fol has e do solo, em um Latossolo Vermelho-Escuro originário do arenito Caiuá no Noroeste do Paraná.

\section{MATERIAL E MÉTODOS}

Foi utilizado um experimento de campo delaranja pêra (Citrus sinensis (L.) Osbeck) sobre o portaenxerto limão-cravo (Citrus limonia Osbeck) no espaçamento de $7 \times 4$ m, plantado em 31/08/93, no município de Alto Paraná, Noroeste do Paraná, em um Latossolo Vermel ho-Escuro textura média, originário da formação geológica do arenito Caiuá, em área anteriormente ocupada por pastagem Brachiaria humidicola.

Neste experimento, estavam sendo estudados seis sistemas de manejo do solo nas entrelinhas: (1) legumi nosa calapogônio Cal opogonium mucronoides; (2) leguminosa amendoi $m$ forragei ro Arachis pintoi; (3) gramínea mato grosso Paspalum notatum; (4) vegetação espontânea com predominância de Brachiaria humidicola; (5) preparo do sol o em faixas com a manutenção da pastagem remanescente na entrelinha (Brachiaria humi dicola) e (6) cultivo de abacaxi intercalar. O delineamento experimental desse experimento apresentava blocos ao acaso com três repetições, sendo cada parcela útil constituída de três plantas centrais, disposta em linha, apresentando bordadura de duas plantas entre as parcelas úteis na linha de plantio e duas linhas de plantas entre os blocos.

A calagem de 2 t ha-1 de cal cário dol omítico que precedeu a instalação do experimento foi aplicada a lanço em área total, em 03/02/93, seguida do preparo convencional do solo com uma gradagem pesada, uma aração profunda egradagens niveladoras, exceto no tratamento de preparo do solo em faixas com a manutenção da pastagem remanescente na 
entrelinha, onde o preparo de solo foi realizado somente na faixa de $2 \mathrm{~m}$ destinada ao plantio, mantendo-se nas entrelinhas a vegetação remanescente.

As covas de plantio de laranja $(0,4 \times 0,4 \times 0,4 \mathrm{~m})$ receberam a seguinteadubação: $100 \mathrm{~g} \mathrm{de}_{2} \mathrm{O}_{5}, 30 \mathrm{~g}$ de $\mathrm{K}_{2} \mathrm{O}, 5 \mathrm{~g}$ de $\mathrm{Zn}$ e $2 \mathrm{~g}$ de $\mathrm{B}$. O abacaxi, cultivar Smooth Cayenne, foi plantado em duas fileiras duplas com mudas tipo filhote, no espaçamento de $0,9 \times 0,4 \times 0,4 \mathrm{~m}$, a partir de 1,5 m da linha de plantio da laranja, em outubro de 1993. Como adubação, no sulco de plantio, foram aplicados $10 \mathrm{~g}$ de $\mathrm{P}_{2} \mathrm{O}_{5}$ por metro linear de sulco. $\mathrm{Na}$ adubação de cobertura, foram empregados $12 \mathrm{~g}$ de $\mathrm{N}$ e $24 \mathrm{~g}$ de $_{2} \mathrm{O}$, divididos em 4 parcelas nos anos de 1993 e 1994. Na fase de desenvolvimento vegetativo, foram realizadas três pulverizações fol iares com uréia e sul fato de potássio a 3\%. A cultura do abacaxi foi mantida nolimpo por meio de capinas manuais e uso de herbicidas específicos. A pós a col heita final dos frutos em janeiro de 1996, a soqueira foi retirada em abril de 1996 e as entrelinhas deste tratamento ocupadas por vegetação espontânea. O calopogônio foi plantado em outubro de 1994, col ocando-setrês sementes por cova, no espaçamento de $0,5 \times 0,5 \mathrm{~m}$. O amendoim forrageiro, cultivar Amarilo MG-100, também foi plantado em outubro de 1994, colocando-se três sementes por cova, no espaçamento de 0,3 x 0,5 m. Mudas de grama mato grosso foram plantadas em abril de 1993, no espaçamento de 0,5 x 0,5 m.

O manejo das entrel inhas do pomar foi realizado por meio de roçadeira mecânica, e as faixas de adubação com herbicida, local onde foram real izadas as adubações minerais, seguiram as recomendações técnicas preconizadas à citricultura.

A amostragem foliar foi efetuada em 05/03/96, seguindo o método descrito pelo Grupo Paulista de
Adubação e Calagem para citros (GPACC, 1994), coletando-sea $3 a$ e $4 a$ fol ha a partir do fruto, total izando 24 folhas para cada amostra. Em 24/05/96, foram col etadas amostras de solo nas camadas de 0-20 e 20-40 cm nas faixas adubadas e nas entrelinhas, constituídas de seis subamostras por amostra. As deter mi nações analíticas das amostras foliares e de sol o foram efetuadas conforme método utilizado pel o laboratório desolos do I APAR (Miyazawa et al., 1992; Pavan et al., 1992).

A col heita dos frutos da primeira safra agrícola (1995/96) foi realizada em 01/07/96, determinandose o peso e o número total de frutos por parcela útil.

Os resultados foram submetidos à análise de variância e teste de separação de médias (teste F), determinando-se as correl ações de Pearson (testet) entre a produção, o número de frutos por planta, as características químicas do solo e os teores dos nutrientes foliares. As análises de variância e as correlações dos dados de produção, número de frutos e teores de nutrientes das folhas e do solo foram efetuadas por meio do Statistical Analysis System (SAS, 1989).

\section{RESULTADOSE DISCUSSÃO}

As características químicas do solo das entrelinhas do pomar, na camada de $0-20 \mathrm{~cm}$ de profundidade, apresentaram correlações significativas e positivas entre o $\mathrm{pH}, \mathrm{Ca}, \mathrm{Mg}$, saturação por $\mathrm{Ca}$ e Mg na capacidade de troca de cátions ( $\mathrm{Ca} / \mathrm{T}$ e Mg/ T) e saturação por bases (V) com a produção e número defrutos por planta. Essas correlações foram significativas e negativas com a acidez ( $\mathrm{Al} \mathrm{eH}+\mathrm{Al}$ ) e saturação por acidez potencial na capacidade de troca de cátions $(\mathrm{H}+\mathrm{Al} / \mathrm{T})$ (Quadro 1$)$.

Quadro 1. Coeficientes de correlação entre produção e número de frutos de laranja pêra com os resultados da análise de solo nas entrelinhas e faixas de adubação nas camadas de 0-20 e $20-40 \mathrm{~cm}$ de profundidade de seis sistemas de manejo do solo, no Noroeste do Paraná

\begin{tabular}{|c|c|c|c|c|c|c|c|c|}
\hline \multirow{3}{*}{ Item } & \multicolumn{4}{|c|}{ Produção de frutos por planta (kg) } & \multicolumn{4}{|c|}{ Número de frutos por planta } \\
\hline & \multicolumn{2}{|c|}{ Entrelinha } & \multicolumn{2}{|c|}{ F aixa de adubação } & \multicolumn{2}{|c|}{ Entrelinha } & \multicolumn{2}{|c|}{ F aixa de adubação } \\
\hline & $0-20 \mathrm{~cm}$ & $20-40 \mathrm{~cm}$ & $0-20 \mathrm{~cm}$ & $20-40 \mathrm{~cm}$ & $0-20 \mathrm{~cm}$ & $20-40 \mathrm{~cm}$ & $0-20 \mathrm{~cm}$ & $20-40 \mathrm{~cm}$ \\
\hline $\mathrm{pH}-\mathrm{CaCl}_{2}$ & $0,76 * *$ & $0,65^{* *}$ & 0,16 & 0,18 & $0,72 * *$ & 0,37 & 0,04 & 0,11 \\
\hline Al & $-0,72 * *$ & $-0,74 * *$ & $-0,10$ & $-0,10$ & $-0,62 * *$ & $-0,47$ & $-0,04$ & 0,13 \\
\hline $\mathrm{H}+\mathrm{Al}$ & $-0,52 *$ & $-0,70 * *$ & $-0,33$ & $-0,19$ & $-0,55^{*}$ & $-0,45$ & $-0,28$ & $-0,09$ \\
\hline $\mathrm{Ca}$ & $0,74 * *$ & $0,48^{*}$ & $-0,25$ & 0,10 & $0,60 * *$ & 0,18 & $-0,20$ & 0,04 \\
\hline $\mathrm{Mg}$ & $0,51^{*}$ & $0,54 *$ & $-0,01$ & 0,02 & $0,49 *$ & 0,25 & $-0,09$ & $-0,18$ \\
\hline v & $0,72 * *$ & $0,58 *$ & $-0,09$ & 0,12 & $0,64 * *$ & 0,27 & $-0,11$ & $-0,01$ \\
\hline $\mathrm{Ca} / \mathrm{T}^{(1)}$ & $0,76^{* *}$ & $0,51^{*}$ & $-0,18$ & 0,14 & $0,66^{* *}$ & 0,21 & $-0,14$ & 0,09 \\
\hline $\mathrm{Mg} / \mathrm{T}^{(1)}$ & $0,47 *$ & $0,58^{*}$ & 0,05 & 0,06 & $0,49 *$ & 0,31 & $-0,04$ & $-0,14$ \\
\hline $\mathrm{H}+\mathrm{Al} / \mathrm{T}^{(1)}$ & $-0,72$ & $-0,58^{*}$ & 0,09 & $-0,12$ & $-0,64 * *$ & $-0,27$ & 0,11 & 0,01 \\
\hline
\end{tabular}

(1) Saturação por Ca, Mg e K na capacidade de troca de cátions (T). *, ** significativos a 5 e 1\% pelo teste t, respectivamente. 
Quadro 2. Características químicas de um Latossolo Vermel ho-E scuro textura média, nas faixas adubadas e entrelinhas de pomar de laranja pêra nas camadas de 0-20 e $20-40 \mathrm{~cm}$ de profundidade de seis sistemas de manejo do solo no Noroeste do Paraná

\begin{tabular}{|c|c|c|c|c|c|c|c|c|c|c|c|c|c|c|}
\hline Tratamento & $\mathbf{P}$ & C & pH & Al & $\mathbf{H}+\mathbf{A l}$ & $\mathrm{Ca}$ & $\mathbf{M g}^{(\mathbf{l})}$ & $K^{(1)}$ & $\mathbf{T}^{(\mathbf{1})}$ & $\mathbf{v}$ & $\mathrm{Ca} / \mathrm{T}$ & $M g / T^{(1)}$ & $K / \mathbf{T}^{(\mathbf{1})}$ & $\mathbf{H}+\mathbf{A} \mathbf{l} / \mathbf{T}$ \\
\hline & $\mathrm{mg} \mathrm{dm}^{-3}$ & $\mathrm{gdm}^{-3}$ & $\mathrm{CaCl}_{2}$ & & & $-\mathrm{mm}$ & $\mathrm{dol}_{\mathrm{C}} \mathrm{dm}^{-3}$ & & & & & $-\%$ & & \\
\hline & & & & & & & ixa de ac & dubação & $(0-20 \mathrm{~cm}$ & & & & & \\
\hline $\begin{array}{l}\text { C. mucronoides } \\
\text { Arachis pintoi } \\
\text { Paspalum notatum } \\
\text { Veg. espontânea } \\
\text { Preparo em faixa } \\
\text { Abacaxi }\end{array}$ & $\begin{array}{l}57,5 \\
68,7 \\
88,1 \\
78,2 \\
89,8 \\
48,6\end{array}$ & $\begin{array}{l}5,0 \\
5,3 \\
5,1 \\
4,9 \\
5,9 \\
5,5\end{array}$ & $\begin{array}{l}4,1 \\
4,0 \\
4,0 \\
3,9 \\
4,1 \\
4,1\end{array}$ & $\begin{array}{l}4,0 \\
4,9 \\
4,6 \\
5,3 \\
3,7 \\
4,2\end{array}$ & $\begin{array}{l}33,4 \\
35,9 \\
34,2 \\
35,1 \\
35,1 \\
33,4\end{array}$ & $\begin{array}{l}5,8 \\
5,7 \\
5,9 \\
6,1 \\
6,4 \\
4,8\end{array}$ & $\begin{array}{l}1,6 \\
1,3 \\
1,9 \\
1,2 \\
1,3 \\
1,5\end{array}$ & $\begin{array}{l}1,5 \\
1,3 \\
1,9 \\
1,5 \\
1,5 \\
1,7\end{array}$ & $\begin{array}{l}42,3 \\
44,3 \\
43,9 \\
43,9 \\
44,3 \\
41,4\end{array}$ & $\begin{array}{l}21,0 \\
18,9 \\
21,9 \\
20,1 \\
20,9 \\
19,3\end{array}$ & $\begin{array}{l}13,6 \\
12,9 \\
13,4 \\
13,9 \\
14,4 \\
11,6\end{array}$ & $\begin{array}{l}3,8 \\
3,0 \\
4,2 \\
2,7 \\
3,0 \\
3,6\end{array}$ & $\begin{array}{l}3,7 \\
3,0 \\
4,3 \\
3,5 \\
3,5 \\
4,2\end{array}$ & $\begin{array}{l}79,0 \\
81,1 \\
78,1 \\
79,9 \\
79,1 \\
80,7\end{array}$ \\
\hline Média & 71,8 & 5,3 & 4,0 & 4,4 & 34,5 & 5,8 & 1,5 & 1,6 & 43,3 & 20,3 & 13,3 & 3,4 & 3,7 & 79,7 \\
\hline \multirow[t]{2}{*}{ C.V. (\%) } & 32,2 & 11,0 & 1,6 & 19,0 & 5,0 & 15,2 & 29,0 & 22,7 & 5,5 & 10,0 & 13,7 & 25,5 & 19,1 & 2,5 \\
\hline & \multicolumn{14}{|c|}{ Faixa de adubação (20-40 cm) } \\
\hline $\begin{array}{l}\text { C. mucronoides } \\
\text { Arachis pintoi } \\
\text { Paspalum notatum } \\
\text { Veg. espontânea } \\
\text { Preparo em faixa } \\
\text { Abacaxi }\end{array}$ & $\begin{array}{l}12,0 \\
11,9 \\
15,0 \\
20,7 \\
16,0 \\
13,3\end{array}$ & $\begin{array}{l}4,9 \\
4,2 \\
4,3 \\
4,3 \\
4,3 \\
4,6\end{array}$ & $\begin{array}{l}4,0 \\
3,9 \\
4,0 \\
3,9 \\
3,9 \\
4,1\end{array}$ & $\begin{array}{l}6,5 \\
8,0 \\
7,1 \\
7,7 \\
9,1 \\
5,4\end{array}$ & $\begin{array}{l}35,1 \\
35,9 \\
35,9 \\
35,9 \\
36,8 \\
33,5\end{array}$ & $\begin{array}{l}9,1 \\
6,6 \\
7,5 \\
7,5 \\
7,4 \\
8,0\end{array}$ & $\begin{array}{l}1,7 \\
1,5 \\
1,3 \\
1,6 \\
1,3 \\
2,0\end{array}$ & $\begin{array}{l}1,3 \\
1,3 \\
2,1 \\
1,3 \\
1,2 \\
1,9\end{array}$ & $\begin{array}{l}47,3 \\
45,4 \\
46,8 \\
46,3 \\
46,7 \\
45,3\end{array}$ & $\begin{array}{l}25,7 \\
20,8 \\
23,2 \\
22,4 \\
21,2 \\
26,3\end{array}$ & $\begin{array}{l}19,2 \\
14,6 \\
16,0 \\
16,1 \\
15,7 \\
17,7\end{array}$ & $\begin{array}{l}3,7 \\
3,2 \\
2,8 \\
3,5 \\
2,8 \\
4,4\end{array}$ & $\begin{array}{l}2,8 \\
2,9 \\
4,4 \\
2,9 \\
2,6 \\
4,1\end{array}$ & $\begin{array}{l}74,3 \\
79,2 \\
76,8 \\
77,6 \\
78,8 \\
73,8\end{array}$ \\
\hline Média & 14,8 & 4,4 & 4,0 & 7,3 & 35,5 & 7,7 & 1,6 & 1,5 & 46,3 & 23,2 & 16,6 & 3,4 & 3,3 & 76,8 \\
\hline \multirow[t]{2}{*}{ C.V. (\%) } & 63,5 & 13,2 & 3,6 & 27,2 & 5,0 & 21,4 & 18,9 & 38,7 & 3,6 & 16,1 & 20,5 & 18,1 & 37,1 & 4,9 \\
\hline & \multicolumn{14}{|c|}{ Entrelinha $(0-20 \mathrm{~cm})$} \\
\hline $\begin{array}{l}\text { C. mucronoides } \\
\text { Arachis pintoi } \\
\text { Paspalum notatum } \\
\text { Veg. espontânea } \\
\text { Preparo em faixa } \\
\text { Abacaxi }\end{array}$ & $\begin{array}{l}1,9 \\
2,1 \\
2,9 \\
2,1 \\
2,3 \\
3,1\end{array}$ & $\begin{array}{l}5,3 \\
4,8 \\
5,3 \\
5,8 \\
5,9 \\
5,1\end{array}$ & $\begin{array}{l}4,7 \\
4,6 \\
5,0 \\
4,7 \\
5,0 \\
4,9\end{array}$ & $\begin{array}{l}0,7 \\
1,6 \\
0,0 \\
0,5 \\
0,2 \\
0,1\end{array}$ & $\begin{array}{l}26,7 \\
26,7 \\
24,1 \\
24,8 \\
24,2 \\
24,8\end{array}$ & $\begin{array}{l}8,2 \\
6,7 \\
8,7 \\
7,1 \\
8,0 \\
8,3\end{array}$ & $\begin{array}{l}5,0 \\
4,5 \\
5,0 \\
4,4 \\
6,4 \\
5,0\end{array}$ & $\begin{array}{l}0,6 \mathrm{c} \\
0,7 \mathrm{c} \\
1,1 \mathrm{bc} \\
1,5 \mathrm{ab} \\
0,9 \mathrm{c} \\
1,6 \mathrm{a}\end{array}$ & $\begin{array}{l}40,6 \\
38,7 \\
39,0 \\
37,8 \\
39,4 \\
39,7\end{array}$ & $\begin{array}{l}34,3 \\
30,5 \\
38,0 \\
34,3 \\
38,6 \\
37,4\end{array}$ & $\begin{array}{l}20,3 \\
17,2 \\
22,4 \\
18,7 \\
20,2 \\
20,8\end{array}$ & $\begin{array}{l}12,4 \\
11,4 \\
12,9 \\
11,5 \\
16,2 \\
12,6\end{array}$ & $\begin{array}{l}1,6 \mathrm{~b} \\
1,9 \mathrm{~b} \\
2,7 \mathrm{~b} \\
4,0 \mathrm{a} \\
2,2 \mathrm{~b} \\
4,0 \mathrm{a}\end{array}$ & $\begin{array}{l}65,7 \\
69,5 \\
62,0 \\
65,7 \\
61,4 \\
62,6\end{array}$ \\
\hline Média & 2,4 & 5,4 & 4,8 & 0,5 & 25,2 & 7,9 & 5,1 & 1,1 & 39,2 & 35,5 & 19,9 & 12,9 & 2,7 & 64,5 \\
\hline \multirow[t]{2}{*}{ C.V. (\%) } & 28,0 & 12,6 & 5,0 & 136,4 & 6,3 & 21,7 & 21,2 & 17,3 & 4,8 & 15,8 & 18,5 & 18,0 & 15,2 & 8,7 \\
\hline & \multicolumn{14}{|c|}{ Entrelinha (20-40 cm) } \\
\hline $\begin{array}{l}\text { C. mucronoides } \\
\text { Arachis pintoi } \\
\text { Paspalum notatum } \\
\text { Veg. espontânea } \\
\text { Preparo em faixa } \\
\text { Abacaxi }\end{array}$ & $\begin{array}{l}1,2 \\
1,1 \\
1,4 \\
1,3 \\
1,2 \\
1,2\end{array}$ & $\begin{array}{l}3,8 \\
4,1 \\
4,5 \\
4,4 \\
4,9 \\
4,3\end{array}$ & $\begin{array}{l}4,5 \\
4,4 \\
4,5 \\
4,3 \\
4,4 \\
4,8\end{array}$ & $\begin{array}{l}2,2 \\
3,1 \\
2,4 \\
3,2 \\
3,1 \\
0,8\end{array}$ & $\begin{array}{l}28,0 \\
29,7 \\
28,1 \\
29,5 \\
29,5 \\
26,0\end{array}$ & $\begin{array}{l}8,5 \\
6,7 \\
6,7 \\
6,2 \\
5,6 \\
9,7\end{array}$ & $\begin{array}{l}4,8 a b \\
4,9 a b \\
5,2 a b \\
4,2 a b \\
2,7 b \\
6,4 a\end{array}$ & $\begin{array}{l}0,5 \\
0,5 \\
0,5 \\
0,7 \\
0,7 \\
0,6\end{array}$ & $\begin{array}{l}41,7 a b \\
41,8 a b \\
40,5 a b \\
40,5 a b \\
38,4 b \\
42,8 a\end{array}$ & $\begin{array}{l}32,8 \\
28,9 \\
30,5 \\
27,0 \\
23,2 \\
39,0\end{array}$ & $\begin{array}{l}20,2 \\
16,1 \\
16,5 \\
15,1 \\
14,5 \\
22,7\end{array}$ & $\begin{array}{c}11,4 \mathrm{ab} \\
11,6 \mathrm{ab} \\
12,7 \mathrm{ab} \\
10,2 \mathrm{ab} \\
7,0 \mathrm{~b} \\
14,9 \mathrm{a}\end{array}$ & $\begin{array}{l}1,2 \\
1,2 \\
1,2 \\
1,6 \\
1,7 \\
1,5\end{array}$ & $\begin{array}{l}67,2 \\
71,1 \\
69,5 \\
73,0 \\
76,7 \\
61,0\end{array}$ \\
\hline Média & 1,2 & 4,3 & 4,5 & 2,5 & 28,5 & 7,3 & 4,7 & 0,6 & 41,0 & 30,2 & 17,5 & 11,3 & 1,4 & 69,8 \\
\hline C.V. (\%) & 27,0 & 14,7 & 5,9 & 75,4 & 8,8 & 31,2 & 26,0 & 25,8 & 3,8 & 24,5 & 28,7 & 24,0 & 23,9 & 10,6 \\
\hline
\end{tabular}

(1) Médias seguidas de letras iguais, nas colunas, não diferem estatisticamente pelo teste de Tukey $(P<0,05)$.

As características químicas do solo das faixas de adubação não se correlacionaram com a produção e número de frutos (Quadro 1). Os resultados diferenciados das correlações observados entre as faixas de adubação e entrelinhas podem ser atribuídos aos diferentes sistemas de manejo do sol o nas entrelinhas do pomar.
As correlações entre a produção e número de frutos e os teores de Ca e Mg e a acidez do sol o vêm confirmar a importância dessas características químicas para a obtenção de maior produção de citros em solos originários de baixa fertilidade do arenito Caiuá no N oroeste do Paraná. O fato não é novo, pois trabalhos de pesquisa têm relacionado a 
nutrição e a diminuição na produção dos citros com a acidificação e a diminuição nos teores de $\mathrm{Ca}$ e Mg do solo (Huang, 1983; Pavan \& J acomino, 1998). As ocorrências de "amarelinho" ou CVC (Clorose Variegada dos Citros) e o declínio dos citros também têm sido relacionados com as variáveis de acidez do solo (Wutscher et al., 1980, 1994).

Comteores semel hantes decarbono, as entrelinhas do pomar apresentaram comparativamente maior disponibilidade de $\mathrm{Ca}$ e $\mathrm{Mg}$ e menor acidez, em relaçãoàs faixas deadubação(Quadro 2). A aplicação de fertilizantes nas faixas de adubação provocou redução do $\mathrm{pH}$, menores teores de Ca e Mg emaiores de Al, $\mathrm{P}$ e K.

O cultivo de abacaxi intercalar proporcionou teores esaturação por K e Mg na capacidade de troca de cátions estatisticamente superiores aos do preparo em faixas, respectivamente, nas camadas de 0-20 e 20-40 cm das entrelinhas. É possível quea maior concentração de ânions adicionados ao solo das entrelinhas com as adubações minerais no cultivo do abacaxi tenha mobilizado o Mg, comparada à baixa taxa de dissolução e lento movimento no perfil do solo do calcário dolomítico aplicado sem incorporação no preparo em faixas, fatojá observado em experimento de calagem e gessagem de laranja pêra em Latossolo Vermelho-E scuro do arenito Caiuá do Noroeste do Paraná (Rêgo, 1997).

Os teores foliares de Ca apresentaram correlações significativas e positivas com a produção e número de frutos (Figuras la, b). Na figura la, observa-se que o nível crítico de Ca foliar foi de $29,72 \mathrm{~g} \mathrm{~kg}^{-1}$, correspondentea $90 \%$ da produção máxima defrutos, equivalente ao nível crítico de $30,00 \mathrm{~g} \mathrm{~kg}^{-1}$ recomendado para os citros no Paraná (IAPAR, 1992). O limão-cravo utilizado no presente estudo é considerado o porta-enxerto com melhor desenvolvimento radicular em solos ácidos e apresenta maior resposta à calagem (Pavan \& J acomino, 1998). Em um LatossoloVermel ho-Escuro do arenito Caiuá no N oroeste do Paraná, os teores de Ca promoveram maior distribuição do sistema radicular no perfil do solo de um pomar de laranja pêra sobre limão-cravo em formação (Rêgo, 1997).

O baixo teor de Ca e o alto teor de $\mathrm{K}$ no solo da faixa adubada em relação à entrelinha (Quadro 2) refletiram na absorção radicular de ambos os elementos, causando relação negativa nas fol has (Figura 1c). Tal antagonismo é resultante dos altos teores fol iares de $\mathrm{K}$, superiores a $18 \mathrm{~g} \mathrm{~kg}^{-1}$, associado aos baixos teores de $\mathrm{Ca}$, inferiores a $35 \mathrm{~g} \mathrm{~kg}^{-1}$ (GPACC, 1994), apresentados no quadro 3. Os resultados indicam possível comprometimento nutricional das plantas na produção de frutos, caso seja mantida a adubação anual potássica com baixos teores de Ca no solo, fato este já diagnosticado nos pomares de Iaranja, onde foi constatada baixa disponibilidade de $\mathrm{Ca}$ e $\mathrm{Mg}$ no solo e nas fol has decorrente da baixa reaplicação de calcário,
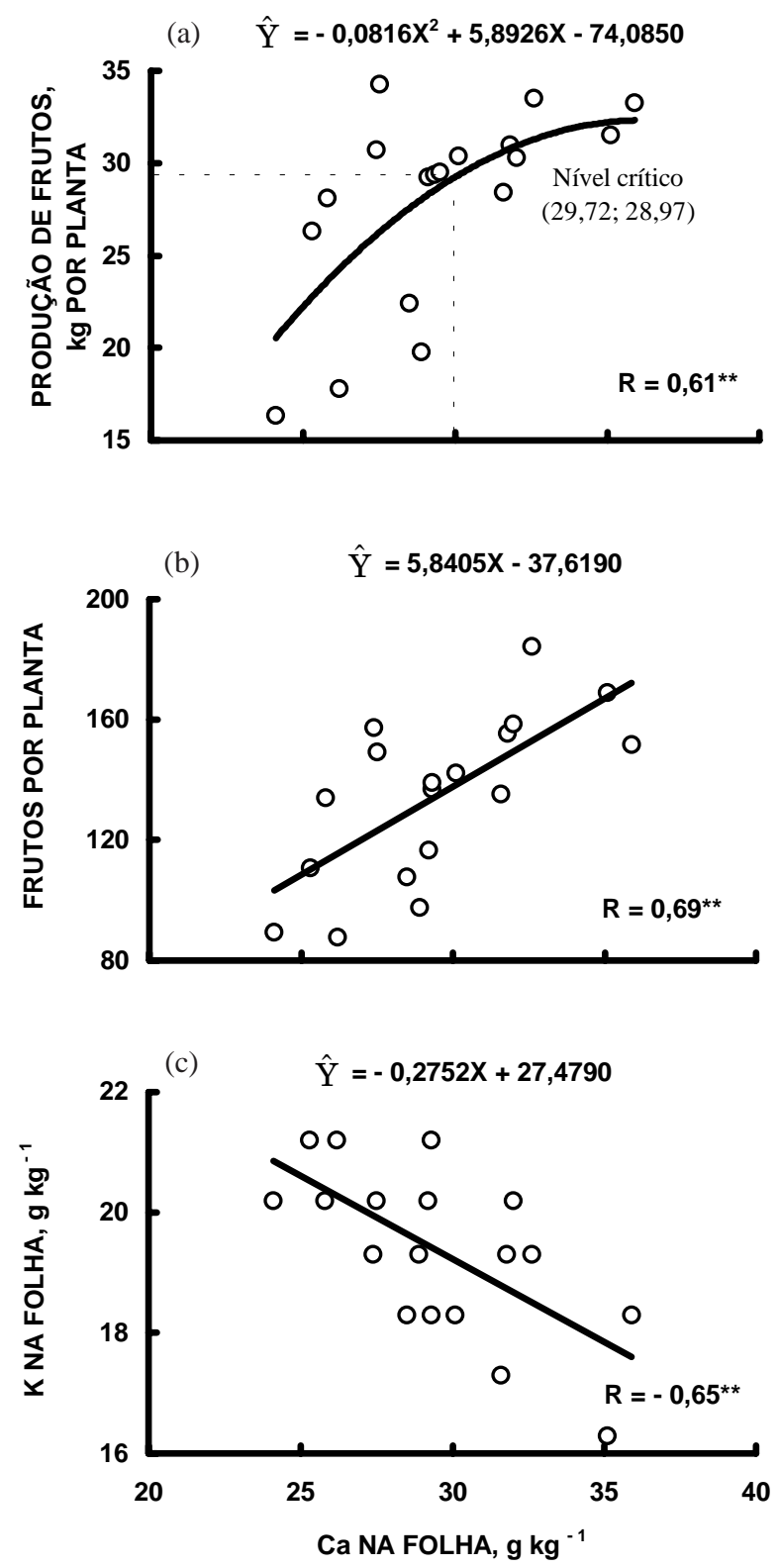

Figura 1. Relações entre produção de frutos (a), número de frutos (b) teores foliares de $K$ (c) e teores foliares de $\mathrm{Ca}$ de seis sistemas de manejo do solo das entrelinhas de pomar de laranja pêra no Noroeste do Paraná.

associada a teores de $\mathrm{K}$ adequados no solo e nas fol has (Fidalski \& Auler, 1997).

Os demais nutrientes apresentaram concentração foliar superior à faixa de suficiência baixa, à exceção do Mg eZn, com teores baixos, inferiores a 2,5 g kg-1 e $35,0 \mathrm{mg} \mathrm{kg}^{-1}$, respectivamente. Os teores fol iares de Zn diferiram significativamenteentre os tratamentos vegetação natural e Arachis pintoi (Quadro 3), não sendo obtida correlação com a produção e número defrutos. 
Quadro 3. Teores foliares de nutrientes em laranja pêra, em um L atossolo Vermelho-E scuro do Noroeste do Paraná em seis sistemas de manejo do solo

\begin{tabular}{|c|c|c|c|c|c|c|c|c|c|}
\hline Tratamento & $\mathbf{N}$ & $\mathbf{P}$ & K & $\mathrm{Ca}$ & Mg & $\mathbf{C u}$ & $Z^{(1)}$ & B & Mn \\
\hline & \multicolumn{5}{|c|}{$-g d^{-3}$} & \multicolumn{4}{|c|}{$\mathrm{mg} \mathrm{dm}^{-3}$} \\
\hline C. mucronoides & 26,1 & 1,2 & 18,3 & 29,2 & 1,2 & 49,2 & $18,2 a b$ & 46,0 & 125,5 \\
\hline Arachis pintoi & 26,9 & 1,2 & 19,9 & 27,7 & 1,2 & 35,0 & $15,3 \mathrm{~b}$ & 44,2 & 127,8 \\
\hline Paspal um notatum & 28,2 & 1,3 & 19,6 & 30,1 & 1,5 & 33,2 & $16,7 a b$ & 55,5 & 176,7 \\
\hline Veg. espontânea & 26,8 & 1,2 & 20,5 & 28,5 & 1,3 & 58,0 & $21,4 a$ & 55,4 & 126,2 \\
\hline Preparo em faixa & 28,0 & 1,3 & 18,0 & 31,4 & 1,3 & 44,2 & $18,9 a b$ & 56,7 & 159,5 \\
\hline Abacaxi & 26,1 & 1,2 & 19,9 & 30,1 & 1,1 & 43,8 & $18,0 a b$ & 39,0 & 153,1 \\
\hline Média & 27,0 & 1,2 & 19,4 & 29,5 & 1,3 & 43,9 & 18,1 & 49,5 & 144,8 \\
\hline C.V. (\%) & 5,1 & 5,3 & 6,4 & 12,3 & 19,7 & 30,5 & 11,6 & 17,5 & 26,7 \\
\hline
\end{tabular}

(1) Médias seguidas de letras iguais, nas colunas, não diferem estatisticamente pelo teste de Tukey $(P<0,05)$.

\section{CONCLUSÕES}

1. A produção e o número de frutos correlacionaram-se positivamente com as características químicas do solo $\mathrm{Ca}, \mathrm{Mg}$, $\mathrm{pH}$ e $\mathrm{V}$ das diferentes modalidades de cobertura do solo das entrelinhas do pomar e, negativamente com a acidez de Al e $\mathrm{H}+\mathrm{Al}$.

2. Os teores foliares de Ca correlacionaram-se positivamente com a produção e número de frutos.

3. O nível crítico de Ca nas folhas foi de $29,72 \mathrm{~g} \mathrm{~kg}^{-1}$.

\section{AGRADE CIMENTOS}

A Alípio Rocha de Menezes, técnico agrícola do IAPAR, pelas contribuições na condução e col eta de dados do experimento. A Osmar Inácio Ferrari, engenheiro-agrônomo, pela cessão da área experimental na Fazenda São J udas Tadeu, Alto Paraná (PR).

\section{LITERATURA CITADA}

EMPRESA BRASILEIRA DE PESQUISA AGROPECUÁRIA EMBRAPA. Serviço Nacional de Levantamento e Conservação de Solos. Levantamento de reconhecimento dos sol os do estado do Paraná. Londrina, Embrapa-SNLCS/ SUDESUL/I APAR, 1984. v.1/2, 791p. (EMBRAPA-SNLCS. Boletim de Pesquisa, 27; IAPAR. Boletim Técnico, 16)
FIDALSKI, J . \& AULER, P.A.M. Levantamento nutricional de pomares de Iaranja no Noroeste do Paraná. Arq. Biol. Tecnol., 40:443-451, 1997.

FIDALSKI, J . Diagnóstico de manejo e conservação do sol o e da água na região Noroeste do Paraná. R. Unimar, 19:845851,1997b.

FIDALSKI, J . Fertilidade do solo sob pastagens, lavouras anuais e permanentes na região Noroeste do Paraná. R. Unimar, 19:853-861, 1997a.

GALLO, J .R. \& RODRIGUEZ, O. Efeitos de al gumas práticas de cultivo do solo, na nutrição mineral dos citros. Bragantia, 19:345-360, 1960.

GRUPO PAULISTA DE ADUBAÇÃO E CALAGEM PARA CITROS - GPACC. Recomendações de adubação e calagem para citros no estado de São Paulo. Laranja, 3.ed. Cordeirópolis, 1994. 27p.

HUANG, W.L. Acid source and its acidification of citrus soils of Taiwan. J . Agric. Res., 32:83-91, 1983.

INSTITUTO AGRONÔMICO DO PARANÁ - IAPAR. A citricultura no Paraná. Londrina, 1992. 288p. (IAPAR. Circular, 72)

MIYAZAWA, M.; PAVAN, M.A. \& BLOCH, M.F. Análisequímica de tecido vegetal. Londrina, IAPAR, 1992. 17p. (IAPAR. Circular, 74)

PAVAN, M.A. \& J ACOMINO, A.P. Root growth and nutrient contents of citrus rootstocks in an acid soil with varied $\mathrm{pH}$. Ci. Cult., 50:56-59, 1998.

PAVAN, M.A.; BLOCH, M.F.; ZEMPULSKI, H.C.; MIYAZAWA, M. \& ZOCOLER, D.C. Manual de análise química do solo e controle dequalidade. Londrina, IAPAR, 1992. 40p. (IAPAR. Circular, 76) 
RÊGO, I.C. Calagem e gessagem num Latossolo Vermel ho-E scuro cultivado com laranjeira pêra sobre limoeiro cravo. Piracicaba, Centro deEnergia Nudear na Agricultura, 1997. 94p. (Tese de Doutorado)

SAS Institute Inc. SAS/STAT User's Guide, Version 6, Fourth Edition. v.1/2. Cary, NC, 1989. 1789p.

SI LVA, J .A.A. Consorciação de adubos verdes na cultura de citros em formação. Piracicaba, Escola Superior de Agricultura “Luiz de Queiroz", 1995. 116p. (Tese de Mestrado)
WUTSCHER, H.K.; SCHWARZ, R.E.; CAMPLIGLIA, H.E.; MOREIRA, C.S. \& ROSSETI, V. Blighlike citrus tree declines in South America and South Africa. Hort. Sci., 15:588-590, 1980.

WUTSCHER, H.K.; PAVAN, M.A. \& PERKINS, R.E. A survey of mineral elements in the leaves and roots of citrus variegated chlorosis (or Amarelinho) affected orange trees and 45 acid extrants elements in the soil of orchards in northern São Paulo and southern Minas Gerais. Arq. Biol. Tecnol., 37:147156, 1994. 